\title{
Meal and Snack Patterns of Infants and Toddlers in the United Arab Emirates: The UAE Feeding Infants and Toddlers Study
}

\author{
Yousef M. Abdulrazzaq ${ }^{a}$ Shahraban Abdullab Ghazala Belhaj ${ }^{\mathrm{c}}$ \\ a Department of Paediatrics, College of Medicine and Health Sciences, UAE University, Al Ain, United Arab Emirates; \\ ${ }^{\mathrm{b}}$ Department of Paediatrics, Latifa Hospital, Dubai, United Arab Emirates; ${ }^{\mathrm{C} D e p a r t m e n t}$ of Paediatrics, Al Ain \\ Hospital, Al Ain, United Arab Emirates
}

\section{Keywords}

Toddlers · Infants · Feeding · Snacks · Breast milk ·

Complementary feed

\section{Abstract}

Aim: To describe meal and snack patterns and practices of infants and toddlers in the UAE. Method: A random sample of 1,000 infants and toddlers, aged 5 months to 2 years and attending Public Health clinics for immunization, was recruited. One face-to-face interview in which caregivers reported the feeding pattern of their infants and toddlers in the preceding 24-h period was conducted. For statistics, we used percentages (proportions) by age group (5-11.9 and 12-24 months). Result: The rate of breastfeeding decreased with age from $60 \%$ at 5 months to $37 \%$ at 12 months. At the age of 5-6 months, $90 \%$ of infants had been introduced to complementary foods. Juice was consumed by $7 \%$ of the infants before the American Academy of Pediatrics-recommended age of 6 months. At the age of 9-11 months, 90$100 \%$ of infants consumed cows' milk on a daily basis. Moreover, French fries and/or sweetened beverages were consumed by $10 \%$ of infants and toddlers. Chicken was the most commonly fed meat $(19.6 \%$ of infants and $57.2 \%$ of toddlers). Conclusion: The study results provide important evidence of improper feeding in some children and would help in providing guidance to parents and caregivers about the introduction of appropriate solid foods at an appropriate time.

(C) 2019 The Author(s)

Published by S. Karger AG, Basel

\section{Introduction}

Breastfeeding is the most appropriate way to provide the body with the required nutrients to promote healthy development and growth, especially in an infant's critical period, i.e., the first year of life [1]. There is supporting evidence that exclusively breastfeeding in the first 6 months of life has great benefits for infants' growth and health, both physiologically and psychologically [2]. Breastfeeding also has a modest protective effect on the development of obesity in childhood, adolescence, and adulthood [3]. Moreover, the World Health Organization (WHO) has recommended that infants should be exclusively breastfed for the first 6 month of life, with no intro- 
duction of any complementary foods or liquids [4]. Despite the availability of such convincing information, only $30 \%$ of children under 6 months of age in Sub-Saharan Africa are exclusively breastfed [5], hence influencing the mortality rates of African children. In a study from the UAE, the exclusive breastfeeding rate was found to be $76.5 \%$ on day $1,48.4 \%$ at 1 month, and $13.3 \%$ at 6 months of age [6]. The National Nutrition Survey in the UAE done in 1992 [7] showed that $42 \%$ of infants received bottle-feeds during the first month, $21 \%$ during the second month, and 9\% during the third month. Another study showed that $70 \%$ of infants received non-milk supplements during the first month of life [8]. According to Osman and El-Sabban [9], 76.1\% of infants were given milk supplements before the end of their first month and only $28 \%$ of the mothers exclusively breastfed their infant. Radwan [10] reported that, although $98 \%$ of mothers initiated breastfeeding, complementary feeds were introduced early and breastfeeding was stopped early.

Complementary foods are often prepared, served and stored under conditions that increase the child's vulnerability to the risk of frequent infections. When complementary foods are introduced prior to 6 months of age, the incidence of diarrheal disease rises [11]. In addition, complementary foods are usually deficient in calcium, zinc, and iron [12]. The WHO has strongly recommended that babies are breastfed exclusively during the first 4-6 months of life [13]. Breast milk plays an important role in preventing various diseases in the perinatal period and also has the long-term benefits of protection from chronic diseases in later life [14]. Moreover, frequent, exclusive breastfeeding during the first 6 months postpartum in developing countries is beneficial to the infant and the mother [15]. The introduction of cows' milk prior to 4 months of age may be associated with an increased risk of developing diabetes [16].

There is a lack of awareness of the right type and amount of nutritious foods for older infants and toddlers. Women with infants and toddlers need to be guided to provide sufficient amounts of essential nutrients and cultivate healthy eating practices to meet their infants' energy and body requirements.

Literature on the dietary status of UAE infants and toddlers remains scarce. This is the first large-scale study on infant feeding practices in the UAE. The main aims of this study are to describe meal and snack patterns of infants and toddlers and assess adherence to infant feeding recommendations among a sample of infants and toddlers aged 5-24 months in the cities of Dubai and Al Ain, UAE.

\section{Methods}

This is a descriptive, cross-sectional study. We calculated the number of infants and toddlers by taking into account the fact that we had to compare a binary variable that occurred in $5 \%$ of children in 1 group and $10 \%$ in the other group, with a 2 -sided significance level of $5 \%$ and a power of $80 \%$. We obtained the number of 475 children per group, but decided to sample 500 children in each group to allow for possible losses. In the UAE, vaccination for $>96 \%$ of infants and toddlers occurs in government-run clinics and primary health care centers. Recruitment of study subjects took place at these centers as they provide good coverage of the target population. We used centers from 2 cities in the Emirates of Dubai and Abu Dhabi (Dubai and Al Ain, respectively), as these cities represent urban (Dubai) and rural (Al Ain) areas of the UAE. Two clinics were randomly selected from each of 8 clinics in Dubai and 5 clinics in $\mathrm{Al}$ Ain.

Families were recruited consecutively from the infants attending primary health care centers for immunization (250 from each of the 4 sites), until the number needed was attained. The study included only infants born to fathers who were UAE nationals and excluded infants of all other nationalities. A sample of 500 infants and toddlers was selected from Dubai and an equal number from Al Ain. There were 500 infants aged 5-11.9 months and 500 toddlers aged 12-24 months.

A single face-to face interview was conducted with each of 1,000 participants who were asked about the breastfeeding pattern of their infants. They were also asked about the timing of the introduction of complementary foods. The information obtained was based on a 24-h dietary recall. They had to provide details of all the foods consumed by the infant including the type of food. Foods consumed outside of the 3 main meals were considered as snacks. The interview included supplementary questions about feeding patterns, growth, and development. It also included questions concerning emerging issues in childhood nutrition and obesity such as toddlers' physical activity levels, TV/video "screen time," and family meals. The results of this part of the study dealing with nutrition quality and quantity have been published previously [17].

Data were entered into a Microsoft Excel spreadsheet and then transferred to SPSS v20 for statistical analysis. As types of food were recorded as string variables, a special routine was written to translate these into the presence/absence of certain food items, e.g., whether or not the string "puree" occurred. Data were aggregated over the entire day of observation to obtain representative values for the daily intake of food items. Simple statistics like percentages were used to depict the prevalence of breastfeeding, the frequency of feeding, and the frequency of the intake of all types of food.

\section{Results}

It was found that $54.2 \%$ of infants aged 5-11.9 months were fed breast milk. However, this decreased to $25.2 \%$ in toddlers 12-24 months of age. Specifically, at 5 months, $60 \%$ of infants were breastfed; at 12 months of age, only $37 \%$ were consuming breast milk. Breastfeeding was continued till 2 years of age in only $20 \%$ of the children (Fig. 1). 
Fig. 1. Breastfed infants and toddlers in the

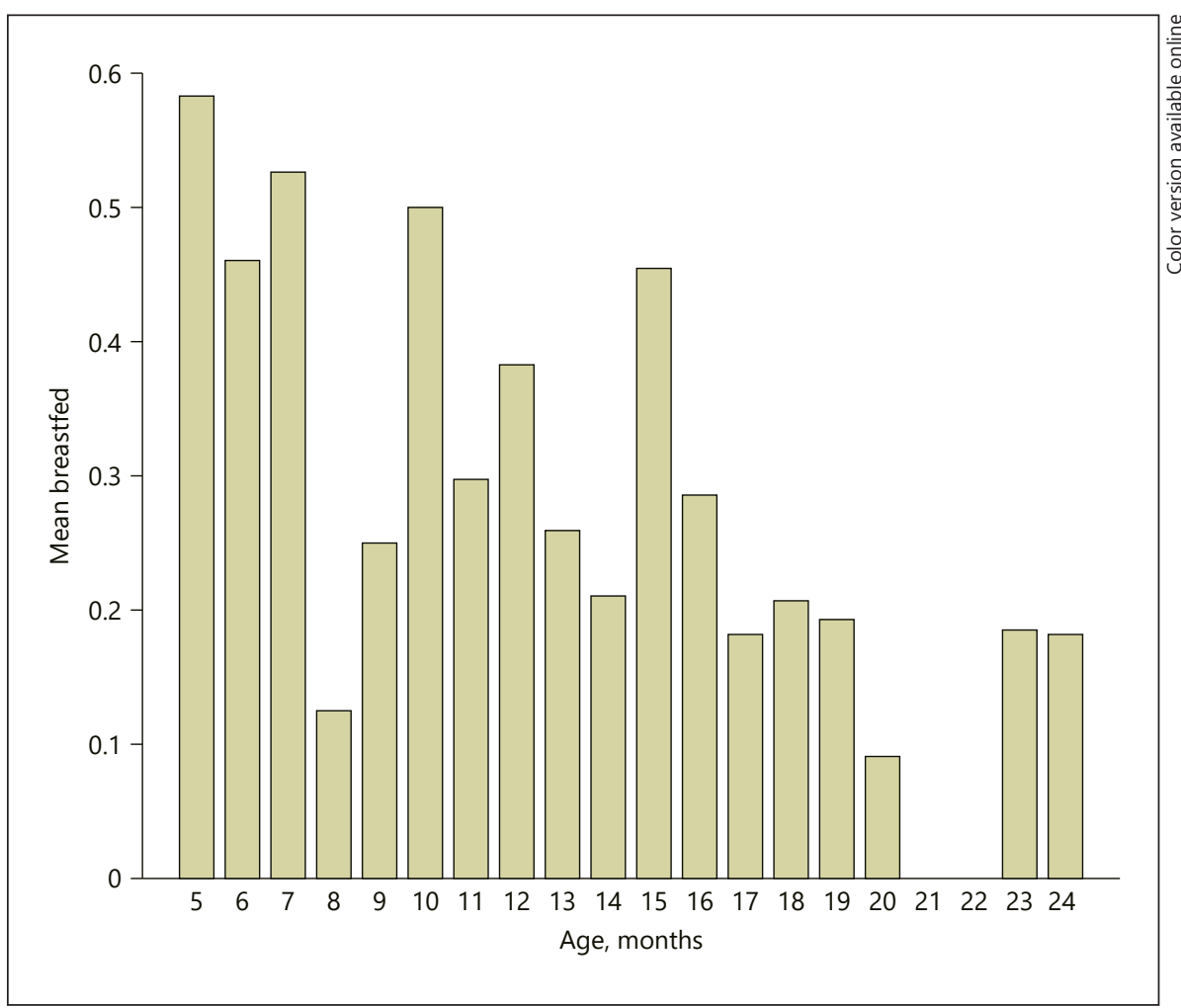
UAE.

About $90 \%$ of the infants aged 5-6 months had been introduced to complementary foods. Juice was taken by $7 \%$ of infants $<6$ months of age, $12.9 \%$ aged 5-11.9 months, and $27 \%$ aged $12-24$ months. It was common for infants aged 5-11.9 months to consume either camel's or cow's milk (in the form of formula) (85.7\%). Between 90 and $100 \%$ of infants aged 9-11 months consumed cows' milk (formula) on a daily basis while $92 \%$ of their counterparts aged 12-24 months consumed camel's or cow's milk (formula). A significantly larger percentage (82.1\%) of the infants in Dubai than in $\mathrm{Al}$ Ain (68.5\%) drank cow's (formula) or camel's milk ( $p<0.01)$. At least $10 \%$ of infants consumed foods such as French fries and/or sweetened beverages on any given day.

Surprisingly, a good percentage of children in both age groups ate vegetables $(62.9 \%$ of infants $5-11.9$ months and $76.7 \%$ of toddlers aged $12-24$ months). The 5 most common fruits eaten by the children were bananas, apples, dates, mangoes, and oranges (Table 1). Dates were fed to only $3 \%$ of infants and $2.9 \%$ of toddlers. Rice, which is a staple UAE diet, was fed to $70.6 \%$ of infants and $93.9 \%$ of toddlers, and pasta (macaroni and noodles) to $6 \%$ of infants and $25.1 \%$ of toddlers, potato to $11 \%$ of infants and $9.4 \%$ of toddlers, and bread to $5.1 \%$ of infants and
Table 1. Fruits eaten by infants and toddlers in the UAE

\begin{tabular}{lll}
\hline & $\begin{array}{l}\text { Infants aged } \\
6-11 \text { months, } \%\end{array}$ & $\begin{array}{l}\text { Toddlers aged } \\
12-23 \text { months, \% }\end{array}$ \\
\hline Banana & 25.7 & 29.1 \\
Apple & 15.7 & 16.1 \\
Dates & 3 & 2.9 \\
Grapes & 0.2 & 0.6 \\
Mango & 2.1 & 16.1 \\
Orange & 1.4 & 2.5 \\
Other fruits & 17.1 & 18.9 \\
\hline
\end{tabular}

$19.9 \%$ of toddlers (Table 2). Almost all toddlers were fed meat (Table 2). Eggs were fed to $9.1 \%$ of infants and $28.9 \%$ of toddlers. Other foods taken by this sample group of children, mostly as snacks, were Nestlé Cerelac ${ }^{\circledR}$, the most widely used $(50.2 \%$ in infants and $20.5 \%$ in toddlers), cornflakes, sandwiches, soups, cakes, oats, biscuits, custard, fruit puree, yoghurt, and cheese (Tables 3). Snacks were eaten between 3 and 5 times daily by all the infants. 
Table 2. Constituents of the main meals of infants and toddlers in the UAE

\begin{tabular}{lcc}
\hline & $\begin{array}{l}\text { Infants aged } \\
5-11.9 \text { months } \\
(n=500)\end{array}$ & $\begin{array}{l}\text { Toddlers aged } \\
12-24 \text { months } \\
(n=500)\end{array}$ \\
\hline Breast milk & $232(54.2 \%)$ & $120(25.2 \%)$ \\
Formula milk & $367(85.7 \%)$ & $439(92 \%)$ \\
Cerelac ${ }^{\circledR}$ & $215(50.2 \%)$ & $98(20.5 \%)$ \\
Vegetables & $269(62.9 \%)$ & $366(76.7 \%)$ \\
Rice & $303(70.8 \%)$ & $449(94.1 \%)$ \\
Pasta (macaroni + noodles) & $26(6.0 \%)$ & $120(25.1 \%)$ \\
Bread & $22(5.1 \%)$ & $95(19.9 \%)$ \\
Potato & $47(11 \%)$ & $45(9.4 \%)$ \\
Red meat & $19(4.4 \%)$ & $73(15.3 \%)$ \\
Fish & $8(1.9 \%)$ & $46(9.6 \%)$ \\
Chicken & $84(19.6 \%)$ & $273(57.2 \%)$ \\
Eggs & $39(9.1 \%)$ & $138(28.9 \%)$ \\
\hline
\end{tabular}

\section{Discussion}

This study is part of a larger study, the UAE Feeding Infants and Toddlers Study (FITS), which aimed at shedding light on infant and toddler feeding, including issues related to the duration of breastfeeding, the use and quantity of human milk substitutes, the timing and introduction of complementary foods, and overall dietary nutrient adequacy [17]. There is a lot to be desired in the way some infants and toddlers are fed in the UAE, although most are fed appropriately. There were no problems with regard to missed meals, unlike skipped meals reported in older children [18]. There was frequent snacking throughout the day, varying between 3 and 5 times daily. Children were introduced to non-milk complementary foods in the appropriate period recommended by the American Academy of Pediatrics (AAP), but were given juice to consume before the AAP-recommended age of $\geq 6$ months. Moreover, cow's milk was given to the children daily before the recommended age of $\geq 12$ months. It is clear from this sample that the favorite weaning food was Cerelac, started early, at 4-6 months of age. There is a place for the nutritional improvement of the snacks given to the infants and toddlers as there were some who were fed chips, commercial juices, cakes, custard, and pizza.

It was good to know that a good percentage of infants and toddlers received vegetables and fruits as snacks. Our findings are similar to those of the USA FITS, which found that $63 \%$ of infants aged $6-8.9$ months and $72 \%$ of
Table 3. Snacks eaten by infants and toddlers in the UAE

\begin{tabular}{lcc}
\hline & $\begin{array}{c}\text { Infants aged } \\
5-11.9 \text { months } \\
(n=500)\end{array}$ & $\begin{array}{c}\text { Toddlers aged } \\
12-24 \text { months } \\
(n=500)\end{array}$ \\
\hline Biscuits & $82(19.2 \%)$ & $99(20.6 \%)$ \\
Cheese & $51(11.9 \%)$ & $183(28.4 \%)$ \\
Soup & $50(11.7 \%)$ & $116(24.3 \%)$ \\
Yoghurt & $111(25.9 \%)$ & $195(40.9 \%)$ \\
Oats & $19(4.4 \%)$ & $43(9 \%)$ \\
Sandwiches & $10(2.3 \%)$ & $41(8.6 \%)$ \\
Cake & $12(2.8 \%)$ & $59(12.4 \%)$ \\
Cornflakes & $9(2.1 \%)$ & $77(16.1 \%)$ \\
Fruit puree & $25(5.8 \%)$ & $5(1 \%)$ \\
Custard & $10(2.3 \%)$ & $23(4.8 \%)$ \\
Pizza & 0 & $5(1 \%)$ \\
Chips & $3(0.7 \%)$ & $36(7.5 \%)$ \\
Juice & $55(12.9 \%)$ & $129(27 \%)$ \\
\hline Total snacks & $85.7 \%$ & $92 \%$ \\
\hline
\end{tabular}

infants aged 9-14.9 months consumed some vegetables [19]. This period is critical for growth and development, and transitions in food consumption occur in this period thus influencing short- and long-term health. In the Czech Republic, the intake of vegetables is between 62 and $77 \%$ during the period 9-24 months of age [20]. Biscuits, yoghurt, and juices are the most common snacks consumed by UAE infants and toddlers. Almost all the infants and toddlers studied received some form of snack. No carbonated drinks were consumed by the infants and toddlers in the sample studied.

Some researchers have reported that mothers of infants who breastfed for longer tend to report greater responsiveness to infant satiety cues $(p \leq 0.01)$ and reduced pressuring in feeding complementary foods $(p<0.05)$. The latter was also true for mothers of toddlers who breastfed for longer $(p<0.01)$ [21]. These results suggest that the infant's cues during breastfeeding determine how the mother responds and may help shape maternal feeding approaches as infants enter a period of complementary feeding, even after controlling for a range of demographic characteristics previously associated with breastfeeding behaviors. However, this association might not exist in the toddler age group as responsiveness to feeding cues was not associated with breastfeeding duration in the toddler sample. We have not looked at the infants' satiety cues, but we can say that the infants in this study received adequate amounts of milk or complementary foods as the growth rate was normal [17]. 
Breastfeeding involves not only food, thereby providing necessary nutrients, but also a sophisticated endocrine signaling system, and it is therefore critical for infants [22]. In the UAE, almost all mothers (98\%) initiate breastfeeding [10], however, we found only $60 \%$ were breastfeeding infants of 5 months of age. This is a good achievement compared to other countries, where fewer infants are still breastfed at 4-6 months, e.g., 54\% in Luxembourg, $37 \%$ in The Netherlands, and $41 \%$ in Japan [23]; however, it was expected that, in the UAE where, traditionally, breastfeeding continues till babies reach the age of 2 years, the percentage of breastfed infants would be higher. The reason for this lower than expected rate of breastfeeding could be that $29 \%$ of the women nowadays are working mothers [24] and their work circumstances may have forced them to abandon breastfeeding earlier than they would have liked, despite the fact that women in the workplace are, by law, provided with breastfeeding periods. Education is a major factor when it comes to studying the length of time mothers continue to breastfeed their infants. Most (95\%) new mothers in the UAE are educated [24]. Several studies and reports reveal that a higher education level correlates with a shorter duration of breastfeeding $[25,26]$. Previous studies on exclusively breastfeeding in the UAE show conflicting results. The UAE Family Health Survey found that $34 \%$ of infants were exclusively breastfed up to 4 months of age [24], while another study found that $46 \%$ were exclusively breast fed at 4-6 months [27]. In contrast, Al-Mazroui et al. [8] found that only $4 \%$ of infants from the city of $\mathrm{Al}$ Ain were exclusively breastfed during the first month of life. Recently, a study on a multicultural population, including Emiratis, reported that the rate of exclusively breastfeeding at 1 and 6 months was 48 and 13\%, respectively [6].

On the whole, the foods given to infants and toddlers were appropriate. However, some of the complementary foods reported were juice, sweetened beverages, and cow's milk, and also solid foods such as potatoes. Complementary foods were introduced early at a relatively high rate (90\%) in this study compared to the $21 \%$ in the Norwegian infant population as well as in Germany and the USA $[28,29]$. It is also higher than in other Arab counties such as Bahrain (62\%) [30]. In Russia, $59.4 \%$ of babies are weaned on fruit juice, followed by fruit puree (18\%), and cereals $(6.4 \%)$ [31]. It is normal for infants and toddlers to have multiple meals and snacks in a day because of their high levels of activity [32]. In this study, generally, infants and toddlers were routinely fed multiple meals a day. Quite a good num- ber of infants $(62.9 \%)$ and toddlers (76.7\%) were fed vegetables as snacks.

In conclusion, our results provide important evidence for appropriate food intake by the majority of infants and toddlers, except for a few children for whom inappropriate feeding was provided. This study would help in providing guidance to parents and caregivers to increase their awareness about the introduction of appropriate solid foods at an appropriate age. The importance of this study is that it sheds light on the lower than expected breastfeeding rates in infants, indicating that the number of children breastfeeding in the first year of life can be improved. Future research is needed to target the factors associated with such feeding patterns.

\section{Acknowledgement}

We are grateful to the Departments of Preventive Medicine in $\mathrm{Al}$ Ain and Dubai, for the tremendous help extended to us in recruiting the infants' caregivers for the study. We also thank Nestlé for providing the funds for the study.

\section{Statement of Ethics}

Since the study is a non-invasive one, it did not expose any physical or psychological harm to the participants in anyway. All data collected from the participants were strictly confidential and anonymous. Informed consent was obtained from the primary care givers and ethical approval was obtained from College of Medicine and Health Sciences Research Ethics Committee and permission was obtained from the heads of the primary healthcare centers.

\section{Disclosure Statement}

The authors have no conflicts of interest to declare.

\section{Funding Sources}

Funding of the project was from a grant by Nestlé Nutrition. The study design was the same as for the USA FITS and was provided by Nestlé Nutrition. However, Nestlé Nutrition had no role or involvement in collection of data, data analysis, interpretation of data, preparation of the manuscript, or the decision to send it for publication. 


\section{References}

1 Batal M, Boulghourjian C, Abdullah A, Afifi R. Breast-feeding and feeding practices of infants in a developing country: a national survey in Lebanon. Public Health Nutr. 2006 May;9(3):313-9.

2 Lanigan JA, Bishop J, Kimber AC, Morgan J. Systematic review concerning the age of introduction of complementary foods to the healthy full-term infant. Eur J Clin Nutr. 2001 May;55(5):309-20.

3 Owen CG, Martin RM, Whincup PH, DaveySmith G, Gillman MW, Cook DG. The effect of breastfeeding on mean body mass index throughout life: a quantitative review of published and unpublished observational evidence. Am J Clin Nutr. 2005 Dec;82(6):1298307.

4 WHO. Nutrition: Infant and young child. Geneva: World Health Organization; 2004.

5 WHO. The Optimal Duration of Exclusive Breastfeeding: A Systematic Review. Geneva: World Health Organization; 2002.

6 Al Tajir GK, Sulieman H, Badrinath P. Intragroup differences in risk factors for breastfeeding outcomes in a multicultural community. J Hum Lact. 2006 Feb;22(1):39-47.

7 UAE Ministry of Health. National Nutrition Survey. UAE; 1992.

8 Al-Mazroui MJ, Oyejide CO, Bener A, Cheema MY. Breastfeeding and supplemental feeding for neonates in Al-Ain, United Arab Emirates. J Trop Pediatr. 1997 Oct;43(5):3046.

9 Osman N, El-Sabban F. Infant feeding practices in Al-Ain, United Arab Emirates. Geneva: World Health Organization; 1999. vol. 5, pp 103-110.

10 Radwan H. Patterns and determinants of breastfeeding and complementary feeding practices of Emirati Mothers in the United Arab Emirates. BMC Public Health. 2013 Feb; 13(1):171.

11 Lartey A, Manu A, Brown KH, Peerson JM, Dewey KG. Predictors of growth from 1 to 18 months among breast-fed Ghanaian infants. Eur J Clin Nutr. 2000 Jan;54(1):41-9.
12 Briend A, Darmon N. Determining limiting nutrients by linear programming: A new approach to predict insufficient intakes from complementary foods. Pediatrics. 2000 Nov: 106(5):1288-9.

13 WHO. Global strategy for infant and young child feeding. The optimal duration of exclusive breastfeeding. Geneva: World Health Organization; 2001.

14 Hanson LA, Korotkova M, Håversen L, Mattsby-Baltzer I, Hahn-Zoric M, Silfverdal SA, et al. Breast-feeding, a complex support system for the offspring. Pediatr Int. 2002 Aug;44(4):347-52.

15 Dewey KG, Cohen RJ, Rivera LL, Canahuati J, Brown KH. Effects of age at introduction of complementary foods to breast-fed infants on duration of lactational amenorrhea in Honduran women. Am J Clin Nutr. 1997 May; 65(5):1403-9.

16 Monte CM, Giugliani ER. [Recommendations for the complementary feeding of the breastfed child]. J Pediatr (Rio J). 2004 Nov; 80(5 Suppl):S131-41. Portuguese.

17 Abdulrazzaq YM, Nagelkerke N, Abdulla S, Belhaj G. Nutrient intake of infants and toddlers in the United Arab Emirates: the Feeding Infants and Toddlers Study. East Mediterr Health J. 2016 Aug;22(5):293-300.

18 Hackett AF, Gibbon M, Sratton G, Hamill L. Dietary intake of 9-10-year-old and 11-12-year-old children in Liverpool. Public Health Nutr. 2002 Jun;5(3):449-55.

19 Siega-Riz AM, Deming DM, Reidy KC, Fox MK, Condon E, Briefel RR. Food consumption patterns of infants and toddlers: where are we now? J Am Diet Assoc. 2010 Dec; 110(12 Suppl):S38-51.

20 Kudlova E, Rames J. Food consumption and feeding patterns of Czech infants and toddlers living in Prague. Eur J Clin Nutr. 2007 Feb; 61(2):239-47.

21 DiSantis KI, Hodges EA, Fisher JO. The association of breastfeeding duration with later maternal feeding styles in infancy and toddlerhood: a cross-sectional analysis. Int J Behav Nutr Phys Act. 2013 Apr;10(1):53.

22 Melnik BC, John SM, Schmitz G. Milk is not just food but most likely a genetic transfection system activating mTORC1 signaling for postnatal growth. Nutr J. 2013 Jul;12(1):103.
23 WHO. Global Databank on Breastfeeding and Complementary Feeding. Geneva: World Health Organization; 2003.

24 Fikri M, Farid S. United Arab Emirates Family Health Survey. Abu Dhabi, United Arab Emirates: United Arab Emirates Ministry of Health; 2000

25 Leung TF, Tam WH, Hung EC, Fok TF, Wong GW. Sociodemographic and atopic factors affecting breastfeeding intention in Chinese mothers. J Clin Psychiatry. 2003, 64(8):966-8.

26 Dubois L, Girard M. Social determinants of initiation, duration and exclusivity of breastfeeding at the population level: the results of the Longitudinal Study of Child Development in Quebec (ELDEQ 1998-2002). Can J Public Health. 2003 Jul-Aug;94(4):300-5.

27 Osman NA, el-Sabban FF. Infant-feeding practices in Al-Ain, United Arab Emirates. East Mediterr Health J. 1999 Jan;5(1):103-10.

28 Kersting M, Alexy U, Sichert-Hellert W, Manz F, Schöch G. Measured consumption of commercial infant food products in German infants: results from the DONALD study. Dortmund Nutritional and Anthropometrical Longitudinally Designed. J Pediatr Gastroenterol Nutr. 1998 Nov;27(5):547-52.

29 Hediger ML, Overpeck MD, Ruan WJ, Troendle JF. Early infant feeding and growth status of US-born infants and children aged 4-71 mo: analyses from the third National Health and Nutrition Examination Survey, 19881994. Am J Clin Nutr. 2000 Jul;72(1):159-67.

30 Musaiger AO. Food habits in Bahrain: infants feeding habits. J Trop Pediatr. 1983 Oct;29(5): 248-51.

31 Baturin AK. Weaning practices in other parts of the world: case study Russia. Nestlé Nutr Inst Workshop Ser Pediatr Program. 2011;68: $117-25$.

32 Kleinman RE, Greer FR, editors; American Academy of Pediatrics Committee on Nutrition. Complementary feeding. Pediatric $\mathrm{Nu}-$ trition Handbook. 7th ed. Elk Grove Village (IL): American Academy of Pediatrics; 2014 pp. 123-39. 